\title{
Fetal Hydrops in a Twin Pregnancy
}

\section{Melanie McClain 1 , Scott O Guthrie ${ }^{2 *}$}

${ }^{1}$ Lincoln Memorial University - DeBusk College of Osteopathic Medicine, Harrogate, TN

${ }^{2}$ Division of Neonatology, Department of Pediatrics, Vanderbilt University School of Medicine, Nashville, TN

\begin{abstract}
A monozygotic twin diagnosed in utero with fetal hydrops of unknown etiology was severely dysmorphic and had no heart sounds upon delivery. The presentation and autopsy results led to suspicion of an acardiac twin. The complications present in the surviving twin may have been prevented with earlier diagnosis and increased awareness among healthcare providers.
\end{abstract}

Keywords: Twin reversed arterial perfusion sequence; Acardiac anceps

\section{Introduction}

Hydrops fetalis is a well known condition with an extensive list of differential diagnoses. The etiology is divided into immunerelated and nonimmune-related types, and currently almost $90 \%$ of cases are associated with the latter category [1]. Among the various nonimmune-related causes, one of the most common are cardiac aberrations [2]. Prenatal ultrasound serves as the initial diagnostic tool for evaluation of nonimmune hydrops fetalis [3]. We report a case of prenatally diagnosed fetal hydrops in a stillborn twin, the suspected cardiac etiology, and the effects on the surviving twin.

\section{Case Report}

An 18 year old gravida 2 para 2 female gave birth to monochorionic, diamniotic twins at 30 weeks and 4 days gestation. Due to Twin A's growth failure and poor bio-physical profile, delivery was induced. Twin A was born via spontaneous vaginal delivery and Twin B was subsequently delivered by cesarean section after failure to progress during attempted vaginal delivery. Prenatal ultrasound had led to the diagnosis of fetal hydrops of uncertain etiology in Twin B (Figure 1). The pregnancy had been followed closely by a perinatologist as Twin B had begun to exhibit increasing hydrops since 8 weeks of gestation. Neonatology was emergently called to the delivery due to the undetermined etiology of the severe hydrops and the potential outcome.

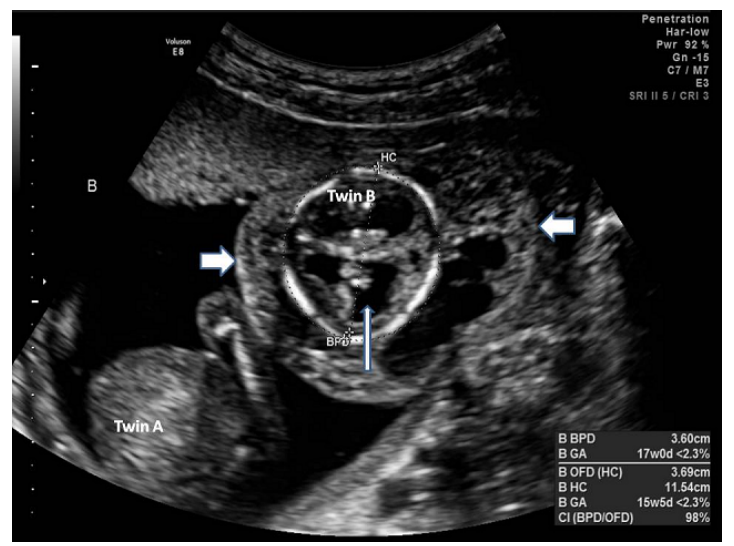

Figure 1: Perinatal ultrasound of Twin B's cranium demonstrating enlarged ventricles (vertical arrow). There is also marked edema (horizontal arrows) surrounding the fetus. Twin A does not show these abnormalities.

\section{Twin A, the surviving twin}

At birth, Twin A weighed $882 \mathrm{~g}$ (3.9 percentile) and measured $32 \mathrm{~cm}(0.1$ percentile) in length. Vital signs and physical exam were within normal limits. The baby was admitted to the neonatal intensive care unit due to prematurity, possible sepsis and respiratory distress. Early neonatal course was normal relative to gestational age except for a coagulopathy which was corrected with fresh frozen plasma and vitamin K. A FISH study was performed to rule out Turner's syndrome and the results were negative. In addition, a chromosomal microarray analysis revealed 46, XX with a partial deletion of chromosome 15.

Cranial ultrasound and echocardiogram were unremarkable except for a moderate patent ductus arteriosus (PDA). After the coagulopathy was corrected, a course of indomethacin was administered for PDA closure. The newborn was treated with four days of phototherapy for jaundice noted on the second day of life. Lab work revealed an elevated direct bilirubin level which steadily decreased over one month with administration of Actigal. Routine surveillance labs, however, showed a rebound in the direct bilirubin and an elevated GGT which led to transfer of the infant to a children's hospital on day 38 of life.

Further evaluation of the baby's conjugated hyperbilirubinemia revealed a large portosystemic fistula comparative in diameter to the infant's descending aorta. Hepatobiliary surgery was consulted, and future embolization was recommended. An umbilical hernia and midgut malrotation were also noted, but no urgent intervention was advised. PDA ligation was performed due to a persistent small to moderate PDA. Further hospital course was uncomplicated, and the infant was discharged home at 126 days of life and a postconceptional age of 48 and $4 / 7$ weeks.

\section{Twin B, the nonviable twin}

Twin B had a stable heart rate by perinatal ultrasound throughout the duration of the pregnancy and during the delivery of Twin A.

*Corresponding author: Scott $\mathrm{O}$. Guthrie MD, Vanderbilt Neonatology Jackson-Madison County General Hospital, 620 Skyline Drive, Jackson TN 38301, USA, Tel: 731-541-3400; Fax: 731-541-6698; E-mail: scott.o.guthrie@Vanderbilt.edu

Received December 02, 2011; Accepted January 11, 2012; Published January 21, 2012

Citation: McClain M, Guthrie SO (2012) Fetal Hydrops in a Twin Pregnancy. J Neonatal Bio 1:102. doi:10.4172/2167-0897.1000102

Copyright: (c) 2012 McClain M, et al. This is an open-access article distributed under the terms of the Creative Commons Attribution License, which permits unrestricted use, distribution, and reproduction in any medium, provided the original author and source are credited. 


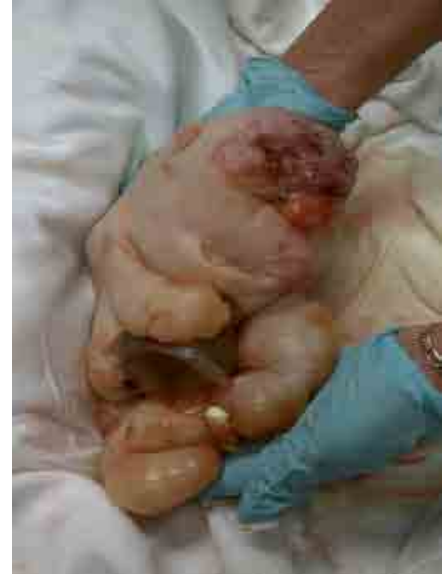

Figure 2: The dysmorphic and edematous presentation of Twin B at delivery.

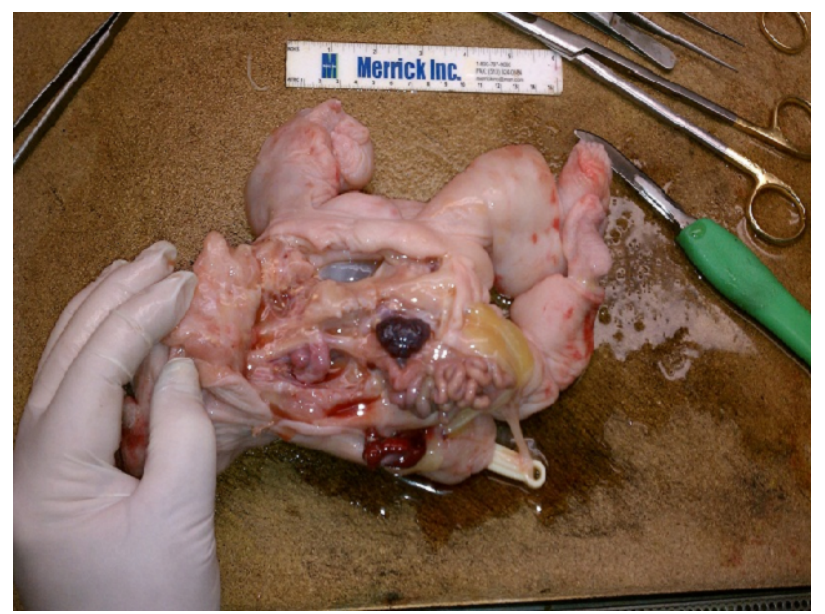

Figure 3: The absence of well-developed internal organs in Twin B at autopsy.

However, upon its own delivery the twin was noted to be severely hydropic (Figure 2) and had absent heart sounds. A careful exam and subsequent autopsy revealed several congenital anomalies (Figure 3 ), which suggested the presentation of an acardiac twin. There were multiple craniofacial abnormalities, including a severe cleft palate, malformed nares and fused eyelids. Hydranencephaly with severe hypoplasia of cerebral tissue and coalesced choroid plexus tissue was noted. Marked global edema was present. An omphalocele contained remnants of the small intestine, liver and spleen.

Many visceral deformities existed, including an absent diaphragm, a hypoplastic heart with two ventricular chambers, bilateral pulmonary hypoplasia and renal agenesis. The sex was indeterminate due to incomplete development of the pelvis and internal genitalia. Diepoxybutane breakage studies were performed on tissue fibroblasts to evaluate for Fanconi syndrome and the results were negative. Evaluation for infectious etiology was also unremarkable, and the cytogenetic testing revealed a normal female karyotype.

\section{Discussion}

Twin reversed arterial perfusion (TRAP) sequence, also referred to as acardiac anomaly, is a rare congenital abnormality that has been detected in $1 \%$ of monochorionic twin pregnancies [4,5]. This unique complication involves the presence of an "acardiac twin" with an absent or nonfunctional heart who is perfused through placental arterial anastomoses by its "pump twin" [5]. The acardiac twin is nonviable, and the perinatal mortality rate for the pump twin is typically over fifty percent if no treatment is provided [5]. Acardius anceps is a rare subcategory of this anomaly and refers to an acardiac twin with partial development of cranial features [6].

While the cases of acardius anceps are not as frequent as other varieties of this already rare malformation, this subtype has been identified as a possible prognostic indicator of unfavorable obstetrical outcome [7]. In addition, if the weight ratio of the acardiac twin is greater than $70 \%$ relative to the weight of the pump twin, the prognosis of the surviving twin is less favorable [8]. In our case, the weight ratio of $122 \%$ is consistent with the newborn's preterm delivery and the consequences of her increased cardiac output to provide blood flow to such a large recipient twin.

Studies of experimental animals have demonstrated that oxygen deficiency during the early stages of embryogenesis can alter the normal development of the head, brain, and heart [9]. With this principle in mind, it is apparent that disruption in oxygen supply due to TRAP sequence may provoke the changes to these organs in acardius anceps [9]. It has been proposed that an occlusion of the abdominal and thoracic vessels is the cause of thrombosis in the umbilical vessels of acardiac twins, leading to limited or no organ development of upper abdominal and thoracic organs in the nonviable twin [10].

Early and accurate antenatal diagnosis by ultrasound is very important for survival of the pump twin [11]. Management options to improve the survival of the pump twin by occluding blood flow to the acardiac twin have been successfully investigated, however, a definitive approach to decrease mortality has not yet been identified [12]. This case serves as a reminder that in twin pregnancies with fetal hydrops, an acardiac twin should be considered and appropriate post-mortem studies should be requested when the index of suspicion is high. Appropriate early evaluation, efficient documentation and collaboration among perinatologists and neonatologists are imperative to provide successful management and improved prognosis for the surviving twin.

\section{References}

1. Speer ME (2011) Postnatal care of hydrops fetalis. UpToDate, Waltham, MA.

2. Lallemand AV, Doco-Fenzy M, Gaillard DA (1999) Investigation of nonimmune hydrops fetalis: multidisciplinary studies are necessary for diagnosis--review of 94 cases. Pediatr Dev Pathol 2: 432-439.

3. Jones DC (1995) Nonimmune fetal hydrops: diagnosis and obstetrical management. Semin Perinatol 19: 447-461.

4. Mikovic Z, Karadzov-Orlic N, Marinkovic M, Djuricic S, Egic A, et al. (2011) Multifetal pregnancies complicated by reversed arterial perfusion: report of four cases. Srp Arh Celok Lek 139: 233-238.

5. Holland MG, Mastrobattista JM, Lucas MJ (2011) Diagnosis and management of twin reversed arterial perfusion (TRAP) sequence. UpToDate, Waltham, MA.

6. Tongson-Ignacio JE, Parveen Z, Thompson K, Hardman JM (2006) Intrauterine fetal demise, male fetuses (monozygotic twins). Holoacardius, acardius anceps type. Arch Pathol Lab Med 130: 90-92.

7. Hanafy A, Peterson CM (1997) Twin-reversed arterial perfusion (TRAP) sequence: case reports and review of literature. Aust N Z J Obstet Gynaecol 37:187-191.

8. Moore TR, Gale S, Benirschke K (1990) Perinatal outcome of forty-nine pregnancies complicated by acardiac twinning. Am J Obstet Gynecol 163 907-912. 
9. Sergi C, Schmitt HP (2000) Central nervous system in twin reversed arterial perfusion sequence with special reference to examination of the brain in acardius anceps. Teratology 61: 284-290.

10. Wolf HK, MacDonald J, Bradford WB, Lanman JT Jr (1991) Acardius anceps with evidence of intrauterine vascular occlusion: report of a case and discussion of the pathogenesis. Pediatr Pathol 11: 143-152.
11. Sohi I, Chacko B, Masih K, Choudhary S (2003) A case of TRAP sequence: acardiac twin. Indian J Pathol Microbiol 46: 664-665.

12. Hecher K, Lewi L, Gratacos E, Huber A, Ville Y, et al. (2006) Twin reversed arterial perfusion: fetoscopic laser coagulation of placental anastomoses or the umbilical cord. Ultrasound Obstet Gynecol 28: 688-91. 